University of Nebraska - Lincoln

DigitalCommons@University of Nebraska - Lincoln

Faculty Publications from the Harold W. Manter Laboratory of Parasitology

2010

\title{
Soil-Transmitted Helminthiases: Implications of Climate Change and Human Behavior
}

Haylee J. Weaver

Australian National University, haylee.weaver@anu.edu.au

John M. Hawdon

George Washington University Medical Center

Eric P. Hoberg

USDA-ARS, eric.hoberg@ars.usda.gov

Follow this and additional works at: https://digitalcommons.unl.edu/parasitologyfacpubs

Part of the Parasitology Commons

Weaver, Haylee J.; Hawdon, John M.; and Hoberg, Eric P., "Soil-Transmitted Helminthiases: Implications of Climate Change and Human Behavior" (2010). Faculty Publications from the Harold W. Manter Laboratory of Parasitology. 736.

https://digitalcommons.unl.edu/parasitologyfacpubs/736

This Article is brought to you for free and open access by the Parasitology, Harold W. Manter Laboratory of at DigitalCommons@University of Nebraska - Lincoln. It has been accepted for inclusion in Faculty Publications from the Harold W. Manter Laboratory of Parasitology by an authorized administrator of DigitalCommons@University of Nebraska - Lincoln. 


\title{
Soil-transmitted helminthiases: implications of climate change and human behavior
}

\author{
Haylee J. Weaver ${ }^{1 *}$, John M. Hawdon ${ }^{2}$ and Eric P. Hoberg ${ }^{3}$ \\ ${ }^{1}$ National Center for Epidemiology and Population Health, The Australian National University, 0200 ACT Australia \\ ${ }^{2}$ Laboratory of Nematode Biology, Department of Microbiology Immunology and Tropical Medicine, The George Washington \\ University Medical Center, Washington, DC 20037, USA \\ ${ }^{3}$ US National Parasite Collection, Animal Parasitic Diseases Laboratory, USDA, Agricultural Research Service, BARC East 1180 , \\ Beltsville, MD 20705, USA
}

\begin{abstract}
Soil-transmitted helminthiases (STHs) collectively cause the highest global burden of parasitic disease after malaria and are most prevalent in the poorest communities, especially in sub-Saharan Africa. Climate change is predicted to alter the physical environment through cumulative impacts of warming and extreme fluctuations in temperature and precipitation, with cascading effects on human health and wellbeing, food security and socioeconomic infrastructure. Understanding how the spectrum of climate change effects will influence STHs is therefore of critical importance to the control of the global burden of human parasitic disease. Realistic progress in the global control of STH in a changing climate requires a multidisciplinary approach that includes the sciences (e.g. thermal thresholds for parasite development and resilience) and social sciences (e.g. behavior and implementation of education and sanitation programs).
\end{abstract}

\section{The burden of soil-transmitted helminthiases}

Soil-transmitted helminthiases (STHs) are intestinal nematodes (Ascaris lumbricoides, Trichuris trichiura and the hookworms Ancylostoma duodenale and Necator americanus) infecting humans and are included in the World Health Organization list of Neglected Tropical Diseases. STHs remain common across the world, especially among poor populations, with more than 1.2 billion people worldwide infected with one or both species of hookworms [1-3] and multispecies infections (polyparasitism) of individuals are common. Using disability adjusted life years (DALYs) as a quantitative measure of disease burden, STHs cause more morbidity than any other parasitic disease except malaria [4]. In China, where 194 million people are infected [5], hookworm causes the loss of more DALYs collectively than lymphatic filariasis, Japanese encephalitis and malaria among women of childbearing age [4]. The impact that these infections have on health varies depending on the intensity of infection and the species, but STHs are regarded as the most important cause of physical and intellectual growth impairment [6]. Children bear the

Corresponding author: Weaver, H.J. (haylee.weaver@anu.edu.au)

Current address: Division of Biomedical Science and Biochemistry, Research School of Biology, The Australian National University, 0200 ACT Australia. highest burden of disease caused by ascariasis and trichuriasis, resulting in malnutrition, growth wasting and stunting, with cognitive and educational deficits [6]. In contrast, although hookworm infections of great intensity occur in children, with similar developmental outcomes as those for ascariasis and trichuriasis, they can also be abundant in adults. Hookworm causes anemia that becomes increasingly severe as infection intensifies, which is a particular problem for pregnant women [7]. With such a high burden of disease causing physical and/or mental impairment, these parasites have a significant effect on the productivity of infected people, from an educational, economic and public health perspective [6].

Effective responses to STHs are an integral part of achieving several of the Millennium Development Goals of the United Nations [7,8], and therefore control or elimination of these helminths should be a high priority. The assemblage of STHs has been demonstrably controlled or eliminated in some areas of the world. Although the potential for broader and more successful control is apparent, the question must be asked: Why are over a billion people still suffering from the diseases caused by STHs? Anthelmintics have been used to control helminths in humans since the $1970 \mathrm{~s}$ [9]. Although mass drug administration programs, coupled with education about parasites and hygiene, have been helpful in the control of STHs, the main impediment to comprehensive control appears to be a lack of understanding of the factors that determine the distribution, prevalence and intensity of STH infections [10].

Increased research into novel methods of intervention and understanding the health impacts of STH infections have been suggested as steps forward to facilitate effective control in highly endemic regions [9]. Momentum has also been gathering to approach STH control in an integrated and holistic way [8], in order to achieve results not reliant solely on anthelmintics and which can offer long-term protection through education and improved sanitation. Also important is the recognition that STHs can exacerbate the risk of disease caused by other pathogens, including HIV/AIDS, malaria and tuberculosis [11]. Current evidence indicates that control of STHs can reduce the health impacts and transmission of malaria and HIV/AIDS [8]. 
The co-endemicity of these diseases in poor regions of sub-Saharan Africa leads to considerable challenges for understanding the complexity of relationships among and between pathogens within individual hosts and populations. Climate change has the potential to add a new dimension and complication to the control of STHs. Here, we will address the linkages between parasite development, human behavior and predicted changes in climate with regard to STHs, methods of detecting the effects of climate on parasites and a future with climate change and STH.

\section{Regional climate change and STH}

Recognition of climate change is not new. The Intergovernmental Panel on Climate Change (IPCC) has released four assessment reports summarizing predictions for the future under a regime of accelerated climate change. The Assessment Report 4 by the IPCC included predictions for a 1.1$6.4{ }^{\circ} \mathrm{C}$ increase in global mean surface temperature by 2100 , with the best estimates at $1.0-4.0^{\circ} \mathrm{C}$ [12]. This assessment, however, has been shown to be rather conservative with estimates of the rates and magnitudes of change [13]. The current lack of effective limitations on future greenhouse gas emissions will drive continued warming, and there is a growing understanding that currently predicted scenarios could miss the mark and the magnitude of environmental change could catch us offguard [14]. Climate change alone, irrespective of pathogens and diseases, was recently listed as the biggest threat to global health for the 21st century [15-17].

Regionally, projected impacts of climate change for Africa and Asia are unclear because of restricted facilities and resources and insufficient climate data [18]. For the sub-Saharan region, where the highest prevalence of STH infection occurs, rainfall is predicted to increase along the tropical and eastern parts of Africa, but decrease in southern Africa, especially during the austral winter (June through August) [18]. For parts of Asia, temperatures are projected to increase, but Southeast Asia will warm the slowest relative to the current average recorded temperatures for the region. Summer precipitation is likely to increase in South and Southeast Asia, but decrease in Central and Western Asia [19]. Changes in climatic conditions, as determinants of soil temperature and humidity, can influence parasites directly (e.g. through facilitating expansion and/or shifts of STHs beyond their current ranges or elimination from some regions). Climate can also influence parasite prevalence and abundance indirectly (e.g. as a result of socioeconomic processes such as altered agricultural practices or reduced food availability).

Despite this apparent level of uncertainty in the rate and predicted outcomes of climate change, important questions emerge regarding the implications for human health [20]. The intricacies and complexity of parasite life cycles and ecologies mean that a diverse array of micro- and macroparasites will be susceptible in varying degrees to long-term environmental change [21,22]. The fact that hosts are also affected by climate change in both direct and indirect ways further increases the complexity of the interactions. How will STHs and their hosts be affected by climate change?

\section{Understanding linkages between climate and parasitism}

Research examining the causal relationships between climate, climate change and STH ecology is the focus of increased attention [23]. Understanding how STHs are likely to be affected by climate change requires an examination of the interactions between climate and parasite ecology and transmission (Figure 1). The distribution,

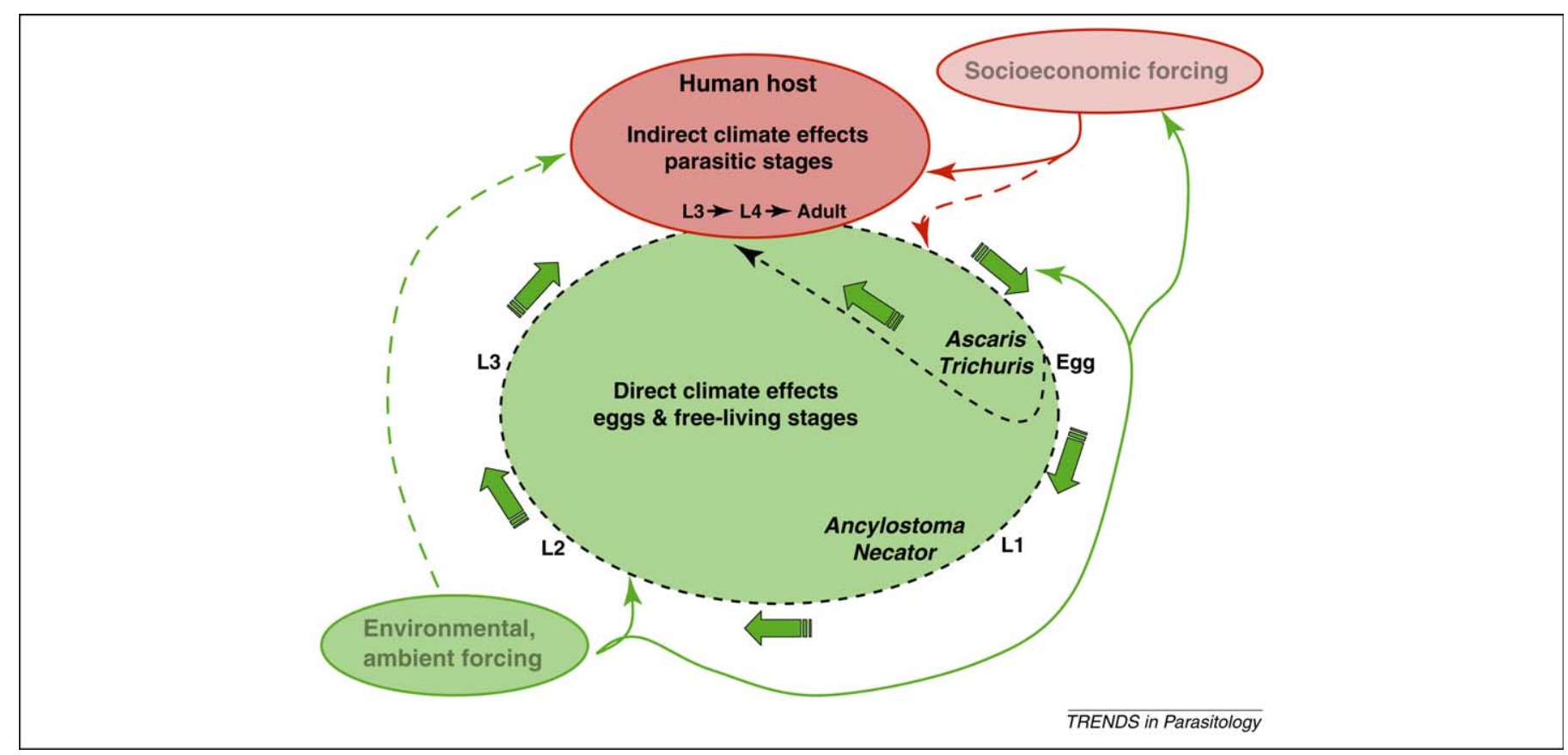

Figure 1. General life cycle pathways shown for hookworms (Ancylostoma and Necator) and for Ascaris and Trichuris. Environmental or ambient forcing will exert the greatest influence on eggs and free-living stages, and indirectly (dashed line) on conditions for human hosts. Socioeconomic forcing will directly influence parameters for infections in human hosts and outcomes for disease, but indirectly will contribute to conditions in the ambient environment via the development and distribution of parasites. 
prevalence and abundance of a parasite is determined by availability of susceptible hosts, environmental thresholds for development (for either free-living or parasite stages in poikilothermic intermediate hosts and vectors) and resilience, bounded by upper and lower tolerances for survival. Furthermore, life history parameters such as how freeliving stages are distributed in the environment (as eggs or larvae) and the potential for arrested development can interact with climate and shorter-term weather patterns to influence distribution. Thus, to a great extent, the actual or realized distribution of parasites in time and space is influenced largely by climatic factors. These factors also contribute to the ecological parameters determining parasite survival and hence transmission. Thus, the changes in climatic variables can alter parasite ecology by affecting host and geographic distribution, infection pressure, prevalence and intensity of parasites and can do so directly (i.e. via free-living stages) or indirectly (i.e. by affecting hosts) (Figure 2) [24].

Shifts or expansion in distribution, prevalence and intensity of STHs and other parasites will be closely linked with that of their hosts and will be dependent on numerous factors driving change [25]. Increasing rates of landscapelevel to regional perturbation can also lead to novel ecological associations, new contact zones and ecotones, hostswitching and emergence of new zoonotic diseases [26]. Breakdown in control mechanisms is equated with emergence of both existing and novel pathogens; such would be predicted under the influence of chaotic displacement of human populations.

Although there are few data for STHs, empirical examples of climate-driven change have emerged from studies of high latitude systems in the Northern Hemisphere, primarily associated with ungulates [23,27-31]. These studies have indicated the importance of both longterm cumulative change (represented as tipping points) and short-term ephemeral (or extreme) events as determinants of changing patterns of distribution and emergence of helminth-related diseases [23,28-30]. There is growing recognition that incremental climate warming and habitat perturbation can be associated with subtle changes in epidemiology. In contrast, rapid modification and explosive emergence could be linked to isolated events for extremes in temperature, precipitation and humidity.

\section{Climate change and biological development of STHs}

The distribution and prevalence of STHs is influenced by the physical environment and by human behavior (Figure 2). For example, transmission patterns of hookworms in many tropical and subtropical areas have been explored in great detail and emphasize these interactions [10,32-39]. By understanding environmental limits and anticipating or predicting range shifts, we can define better responses to changing climate regimes, parasite prevalence and changing patterns of human exposure.

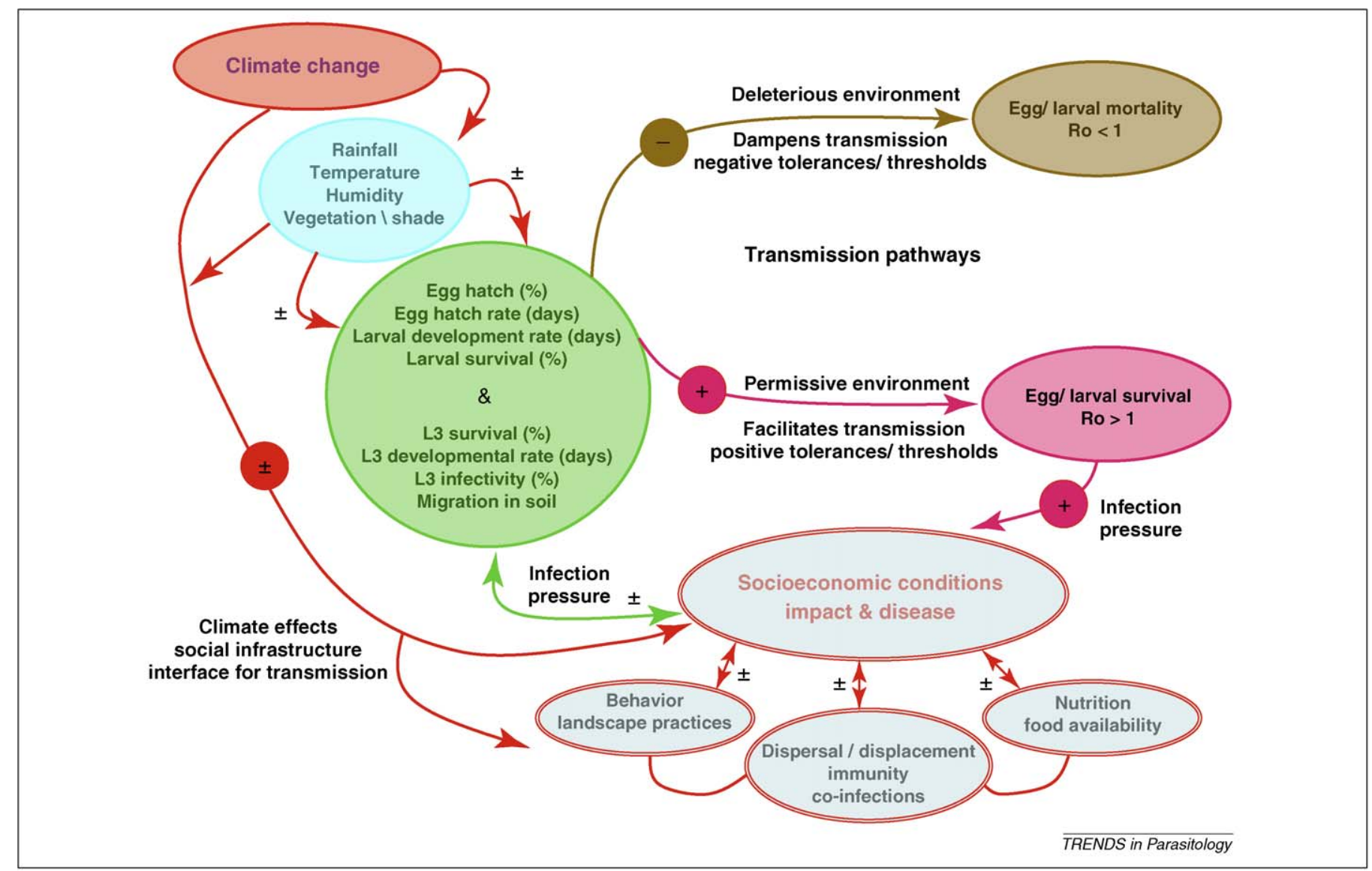

Figure 2. Biological development of STHs, showing the complexity of interactions between potential climatic and socioeconomic factors that will serve as determinants of distribution and disease. 
Table 1. Influence of altered climatic parameters on biological development of STHs associated with climate change

\begin{tabular}{|c|c|}
\hline Climatic variable & Effect on STHs \\
\hline Increased temperature & $\begin{array}{l}\text { Hookworm: } \\
\text { - Increased rate of } L_{1} \text { and } L_{2} \text { development, reducing time taken to infectivity. } \\
\text { - Increased metabolic rate of } L_{3} \text {, negatively affecting survival. } \\
\text { - Temperatures exceeding maximum for development will cause reduced transmission. } \\
\text { A. Iumbricoides and T. trichiura: } \\
\text { - Increase development within egg; decrease time to infectivity. } \\
\text { - Decreased egg viability above certain temperatures. }\end{array}$ \\
\hline Increased precipitation & $\begin{array}{l}\text { All: } \\
\text { - Prevention of egg/larval desiccation, but only to a degree, excessively high rainfall could } \\
\text { reduce egg hatching/larval development. }\end{array}$ \\
\hline Decreased precipitation & $\begin{array}{l}\text { All: } \\
\text { • Reduced egg hatching/larval development. }\end{array}$ \\
\hline Increased relative humidity & $\begin{array}{l}\text { All: } \\
\text { - Prevent desiccation, increase survival rates. } \\
\text { Hookworm: } \\
\text { - Facilitate increased larval survival in soil. }\end{array}$ \\
\hline Decreased relative humidity & $\begin{array}{l}\text { All: } \\
\text { - Facilitate increased larval survival in soil. } \\
\text { Hookworm: } \\
\text { - Reduced larval survival in soil. }\end{array}$ \\
\hline
\end{tabular}

Perpetuation of STH life cycles, effective transmission and maintenance of populations, as with all other infectious pathogens, can be expressed by the basic reproductive number $\left(R_{0}\right)$. A value of 1 or higher indicates that an infection is likely to be sustained in a population [40]. The currently accepted $R_{O}$ values for A. lumbricoides, T. trichiura and hookworm are 1 to 5,4 to 6 and 2 to 3 , respectively [10]. Infective stages of STHs (the eggs of $A$. lumbricoides and T. trichiura, the motile $\mathrm{L}_{3}$ larvae of hookworm) are all dependent on the external environment, specifically the soil. Each of these stages has climatic thresholds for growth and development. Conditions outside these could alter transmissibility either positively or negatively (Table 1). Note, however, that these effects might not all be negative and result in a reduction of transmission.

Interactions between climatic parameters will affect rates of desiccation (and mortality) for eggs of A. lumbricoides and T. trichiura, and hookworm egg hatching success (\%). Overall survival and development of infective $\mathrm{L}_{3}$ could also be affected. The two species of hookworm have differing developmental tolerances and thresholds for ecological parameters $[10,39]$, with $90 \%$ of eggs able to hatch between $15-25{ }^{\circ} \mathrm{C}$ for $A$. duodenale and $20-35{ }^{\circ} \mathrm{C}$ for $N$. americanus [39]. Relative to A. duodenale, distribution of N. americanus might not expand, as it is essentially a tropical parasite with limited resilience. In contrast, A. duodenale is less susceptible to desiccation and already occurs in drier, cooler and more 'marginal' environments. It is potentially a greater problem as it is more virulent and would pose a more substantial challenge under a regime of expansion.

Intensification of drought conditions and increasing temperatures in some areas of Central Africa could serve to limit STH distribution strongly over time [41]. In Central Africa, hookworms have upper survival thresholds exceeding $40-47{ }^{\circ} \mathrm{C}$, in contrast to either A. lumbricoides or $T$. trichiura which do not occur where mean land surface temperatures exceed $37-40{ }^{\circ} \mathrm{C}$ [42-44]. Rainfall exceeding
$1500 \mathrm{~mm}$ annually resulted in $>50 \%$ prevalence for $A$. lumbricoides and T. trichiura in Cameroon [42]. These data suggest that both species are more susceptible to increasing temperature, whereas hookworms are apparently more susceptible to increasing desiccation (Table 1) [10]. Hookworm $\mathrm{L}_{3}$, nonetheless, has the ability to seek appropriate soil microhabitat in deeper layers of the soil to offset unfavorable conditions at ground level. Furthermore, the ability of $A$. duodenale to arrest development upon infection in a host [39], enabling it to 'sit out' unfavorable seasonal conditions could also further complicate the picture of changing patterns of distribution. Although substantial laboratory-derived data for developmental constraints for STHs exist, connecting the dots from these thresholds and tolerances to realized ambient environmental conditions remains a challenge.

Distribution of STHs will most probably fluctuate in and around endemic regions, with increases in transmission and distribution in new areas observed alongside corresponding declines in others; thus, dynamics for transmission on local scales represent a complex mosaic [45], linked both to climate and socioeconomic parameters. For effective control, it is important that the geographic mosaic of increasing and decreasing STH prevalence be identified for various future climate change scenarios, relative to current levels of endemicity.

\section{Socioeconomic aspects of climate change and STH distribution}

Complex sets of biological, behavioral and socioeconomic factors interact and play a large part in the actual or realized distribution of STHs (Figure 2). For example, in an agricultural system present in rural China, human feces (night-soil) have been used for centuries as fertilizer for crops, and multiple determinants contribute to soil larval loads and the potential for infection. Significant among these are crop type, stage of growing season, microenvironment (soil conditions, temperature, moisture) and 
shifting determinants throughout growing season (ambient temperature, precipitation and vegetation changes such as degree of shading). Seasonal extension of favorable conditions can promote northward expansion in rural China. The night-soil route of infection also means that STHs tend to have a focal distribution in rural China, whereas in Africa the more random distribution of human feces leads to a more even pattern of parasites. These examples from China and Africa demonstrate the role of human behavior in STH occurrence.

STH infections might not be an exclusively tropical concern. Recent climate-related events suggest the potential for disease emergence in industrialized regions of the world. For example, emergence of infections and cutaneous larva migrans in Berlin, Germany, of Ancylostoma caninum, a zoonotic hookworm of domestic dogs and free-ranging canids, were associated with periods of extreme and prolonged elevated temperatures and high humidity [24]. This raises the question about modified patterns of larval survival and abundance resulting from the changing climate, and the possibility of extended distributions of infection and/or disease in boreal and temperate latitudes. These shifts in occurrence of $A$. caninum are similar to those for Echinococcus multilocularis in Western and Central Europe and could represent the beginning of emergence of human disease caused by another parasite zoonosis in increasingly urban settings associated with environmental change.

\section{Methods and approaches to predict and identify patterns of change}

STHs remain a substantial burden on socioeconomic development globally, but have not been explored to the same degree as other human parasites and diseases (e.g. malaria and schistosomiasis) in the arena of environmental and climatic change [16,46]. Collectively, human helminthiases, and viral and bacterial diseases, are part of a larger equation that must be understood as the implications of a rapidly changing world become increasingly apparent for human health and wellbeing. Understanding this equation, and more broadly that of emerging infectious diseases, is also dependent on a robust understanding of parasite and host evolutionary history $[47,48]$.

Broadly, there is an increasing call for multi- and interdisciplinary approaches to answer questions about future distribution patterns of pathogens across the realm of infectious diseases and climate change [25,26,49-51]. Numerous tools and programs can be used and implemented to gather the data required to better understand the effects of climate change on STHs (Box 1) [28].

The use of models to understand the effects of climate change is increasing, but their accuracy and applications are dependent on robust data from the field [52]. Predictive modeling has been used with varying degrees of success for diseases such as malaria [53], schistosomiasis [54-56], fascioliasis [57] and nematodiases in ungulates [23], and the broader potential for such methods as ecological niche modeling has been demonstrated [58]. Furthermore, geographic information systems, environmental data and extrapolations of environmental determinants for parasitic development have been used to examine patterns of

\section{Box 1. Toolkit to explore changing conditions for STHs}

- Climate change and cascades

- Identify trends in regional climate change.

- Identify potential responses.

- Identify pathways for mitigation and adaptation.

- Recognize socioeconomic consequences and synergy for climate change and pathogens; incorporate in models.

- Survey, surveillance and mapping

- Link survey to archival collections feeding into informatics and databases for distribution and population genetics.

- Develop rapid molecular based surveillance for geographically extensive and site intensive sampling.

- Explore distributions through geographic information systems.

- Establish baselines for geographic distribution against which to measure changing spatial and temporal patterns.

- Ecological niche modeling, linked to validated biological parameters, as a basis for prediction under regime of accelerated change.

\section{- Population genetics}

- Explore population structure.

- Identify signals for invasive processes and expansion.

- Understand mechanisms for gene flow and isolation.

- Monitor epidemiological and health consequences on fine temporal/spatial scales.

\section{- Validated models}

- Climate based models integrate biotic and abiotic parameters based on tolerances, thresholds and resilience of pathogens in the field.

- Integration of laboratory and field studies.

- Prediction based on sensitivity to climate change.

- Incorporate outcomes linked to human behavior.

distribution of STHs in tropical Africa [11,27,34,35,42,43]. Predicted shifts in distribution of a particular parasite generated by mathematical models to date, however, have not been addressed: (i) how human populations at risk are adapting to climate change; (ii) the demographics and economic status of the population (where richer populations might have more opportunity to deploy control methods [59]); (iii) the state of agriculture and therefore nutrition; (iv) the effects of climate change and environmental perturbations on intermediate hosts or other vectors, and on parasite life cycle stages outside the definitive hosts; and (v) socioeconomic factors that interact with climate serving to either facilitate or dampen the potential for transmission (Figure 2).

\section{A future with climate change and STHs}

Climate change, from an environmental perspective, is predicted to directly influence STHs through its effects on the free-living stages of parasites and have a direct impact on human host populations. Indirect influences on parasite abundances include the effects of altered host nutrition and immunity (Figure 2). Increasing impairment of human health resulting from environmental degradation and climate shifts can amplify environmental mismanagement [60]. The current global inequity between highly developed and developing communities will be exacerbated by climate change [15]. For example, effects of climate change are predicted to result in a 500-fold reduction in life years among poor communities in Africa 
Box 2. Accounting for climate and human behavior: directions and priorities for future control of STHs

Climate change is likely to alter the current circumstances for control of STHs. The following should be considered:

- Climate

- Socioeconomic factors will be directly influenced by climate and environmental changes and will affect our potential responses. How will challenges to health and economic infrastructure affect the current level of control achieved in China, India and Latin America? Are new public health programs required, or will MDA be more appropriate?

\section{- Education}

- Can education programs be used in Africa to reduce prevalence of STHs in populations at risk? What behavioral factors need to change to increase the efficacy of these programs? Does intervention targeted at women have the potential for greatest impact? What are the primary socioeconomic impediments to education (i.e. conflict, high level of poverty, etc.)?

\section{- Novel control strategies}

- Will the novel control methods currently being developed be affected by climate change? Vaccine expiration dates/temperature thresholds, less in-country funding available due to changed priorities, etc.? Will these new control methods be equitable under a regime of a changed climate?

\section{- Modeling and surveillance}

- How can current modeling and surveillance methods be better integrated to identify levels of current risk and new vulnerable areas/populations? What information is most appropriate to produce targeted and regional-specific predictions and responses and to ensure that the most equitable and sustainable methods are used?

relative to comparative climate change conditions in Europe [60]. Droughts, sea level rise and flooding all have demonstrated potential to cause vast displacement of populations at varying temporal and spatial scales. Cumulative processes of climate change and short-term extreme events will exacerbate food scarcity and compromise sanitation and medical services. As a consequence, effects of climate change could be spread disproportionately across poor populations, who lack resources and infrastructure for adaptation or mitigation [20]. In this dynamic regime, we must re-evaluate our approach to understanding the effects of climate change on STHs and other human parasitic diseases, and our approach to control and eradication.

A multidisciplinary approach would greatly enhance the likelihood of success of control of STHs which, to date, has been limited. The urgency of climate change reinforces the necessity of integrated research. Communication and interaction between different disciplines (e.g. parasitology, biochemistry, molecular biology, epidemiology, public health, mathematical modeling, etc.) is imperative to reduce STH infection. Integrated, multidisciplinary approaches to research that have both quantitative and qualitative aspects, and real applicability and impact in the field, can achieve more accurate outcomes that will lead to development of targeted control programs (Box 2).

A thorough understanding of the life history and ecology of parasites alone, however, is not sufficient for the progress that is required on this issue. It is also vital to identify how distribution and health impacts of these parasites are affected by the perturbations linked to climate at regional and global scales. These perturbations can transcend parasite biology and development, resulting in parasitic diseases acting synergistically with other factors (e.g. food availability, water access and population displacement) to create increasingly difficult conditions for life. Main control options for limiting distribution of STHs are related to improving hygiene and sanitation infrastructure (as these are human-specific parasites), which is often linked to socioeconomic development and shifts from pastoral to urban settings. Climate-driven changes in epidemiology in some regions might be circumvented by intervention, adaptation and mitigation. Intervention (sanitation) could be most effective in China, India and South America (Brazil) and could override the influence of environmental effects. For instance, in China there have been major improvements in control (leading to elimination) of some human helminthiases as some regions have shifted away from agriculturally based economies, and people occupy increasingly urban environments where parasites cannot survive in large numbers [61]. In this case, climate might not matter, given that core tools needed to break cycles of transmission are based on socioeconomic development and improved methods for treatment of human waste. In contrast, Africa might not see change in the patterns of parasite occurrence related to economic development in the short term across the tropical sub-Saharan region because of a slower rate of industrialization, although increasingly hot and xeric environments could serve to diminish transmission in this region.

More broadly across the tropics and subtropics, critical questions about impact of climate change and other environmental stressors on STHs are apparent. Will intensity of infection increase (as it is intensity that drives disease)? Will range shifts be accompanied by changing patterns of prevalence and intensity (expansion or shifts with low prevalence and intensity would be predicted to have limited impact on people)? Will increasing industrialization and socioeconomic development offset these changes in parasite ecology?

\section{Concluding remarks}

STHs are a major burden on human health and wellbeing throughout tropical and subtropical regions of the world. The distribution and magnitude of this burden is determined by many factors, including climate and other features of the environment and human behavior. Each of these factors has key roles that vary spatially and temporally. Attempts to determine the effects of climate change and other perturbations on STHs have focused on several investigative targets including: (i) the basic biology and ecology of the parasites; (ii) the effects of measurable environmental changes, including climate, on the prevalence and abundance of infection, incidence and severity of disease; and (iii) predictive models to explore the possible effects of scenarios for the future climate on parasite and disease occurrence. The linkages between STHs, their human hosts and the environment, however, are very complex and none of these approaches alone can provide the answers required for the successful development of adaptive strategies to minimize the impacts of parasites. 
Collaborations between research disciplines and between researchers and workers in the field responsible for individual and community health are essential to improve outcomes for people at risk from these infections. Of equal importance is the identification of risk regions and populations for specific parasites, and understanding the possible impediments to progress. The combined historical disregard for the impacts of STHs as a neglected tropical disease, and of the effects of climate change on these parasites is deep and regrettable, but hopefully reversible.

\section{Acknowledgements}

We thank L. Polley for constructive comments given on the manuscript. Aspects of this review are based on symposium presentations given by H.J.W. and E.P.H. at the World Association for the Advancement of Veterinary Parasitology Conference, 2009.

\section{References}

1 Chan, M-S. (1997) The global burden of intestinal nematode infections - fifty years on. Parasitol. Today 13, 438-443

2 Chan, M-S. et al. (1994) The evaluation of potential global morbidity attributable to intestinal nematode infections. Parasitology 109, 373387

3 World Health Organization (2000) Communicable Diseases: Control of Schistosomiasis and Soil Transmitted Helminth Infections (report by the Secretariat), Executive Board, World Health Organization

4 Murray, C. and Lopez, A., eds (1996) The Global Burden of Disease, World Health Organization

$5 \mathrm{Xu}$, L. et al. (1995) Soil-transmitted helminthiases: nationwide survey in China. Bull. World Health Organ. 73, 507-513

6 Bethony, J. et al. (2006) Soil-transmitted helminth infections: ascariasis, trichuriasis and hookworm. Lancet 367, 1521-1532

7 Hotez, P. and Kamath, A. (2009) Neglected tropical diseases in subSaharan Africa: review of their prevalence, distribution and disease burden. PLoS Negl. Trop. Dis. 3, e412

8 Molyneux, D. (2008) Combating the "other diseases" of MDG 6 changing the paradigm to achieve equity and poverty reduction? Trans. R. Soc. Trop. Med. Hyg 102, 509-519

9 Hotez, P. et al. (2008) Helminth infections: the neglected tropical diseases. J. Clin. Invest. 118, 1311-1321

10 Brooker, S. et al. (2006) Global epidemiology, ecology and control of soiltransmitted helminth infections. Adv. Parasitol. 62, 221-261

11 Hotez, P. et al. (2006) Incorporating a rapid-impact package for neglected tropical diseases with programs for HIV/AIDS, tuberculosis and malaria: A comprehensive pro-poor policy and strategy for the developing world. PLoS Med. 3, 576-584

12 Intergovernmental Panel on Climate Change (2007) Climate Change 2007: The Physical Science Basis. Contribution of Working Group I to the Fourth Assessment Report of the Intergovernmental Report on Climate Change, Cambridge University Press

13 Richardson, K. et al. (2009) Synthesis Report from Climate Change: Global Risks, Challenges and Decisions, Copenhagen 10-12 March, University of Copenhagen

14 Rahmstorf, S. (2007) A semi-empirical approach to projecting future sea-level rise. Science $315,368-370$

15 Costello, A. et al. (2009) Managing the health effects of climate change. Lancet 373, 1693-1733

16 Patz, J. and Olson, S. (2006) Climate change and health: global to local influences on disease risk. Ann. Trop. Med. Parasitol. 100, 535-549

17 Patz, J. et al. (2005) Impact of regional climate change on human health. Nature 438, 310-317

18 Boko, M. et al. (2007) Africa. In Climate Change 2007: Impacts, Adaptation and Vulnerability. Contribution of Working Group II to the Fourth Assessment Report of the Intergovernmental Panel on Climate Change (Parry, M. et al., eds), pp. 433-467, Cambridge University Press

19 Cruz, R. et al. (2007) Asia. In Climate Change 2007: Impacts, Adaptation and Vulnerability. Contribution of Working Group II to the Fourth Assessment Report of the Intergovernmental Panel on Climate Change (Parry, M.L. et al., eds), pp. 469-506, Cambridge University Press
20 Patz, J. et al. (2007) Climate change and global health: quantifying a growing ethical crisis. EcoHealth 4, 397-405

21 Polley, L. (2005) Navigating parasite webs and parasite flow emerging and re-emerging parasitic zoonoses of wildlife origin. Int. J. Parasitol. $35,1279-1294$

22 Patz, J. et al. (2000) Effects of environmental change on emerging parasitic diseases. Int. J. Parasitol. 30, 1395-1405

23 Van Dijk, J. et al. (2010) Climate change and infectious disease: helminthological challenges to farmed ruminants in temperate regions. Animal 4, 377-392

24 Mas-Coma, S. et al. (2008) Effects of climate change on animal and zoonotic helminthiases. Rev. Sci. Tech. OIE 27, 443-452

25 Polley, L. and Thompson, R. (2009) Parasite zoonoses and climate change: molecular tools for tracking shifting boundaries. Trends Parasitol. 25, 285-291

26 Brooks, D. and Hoberg, E. (2007) How will global climate change affect parasite-host assemblages? Trends Parasitol. 23, 571-574

27 Hoberg, E.P. et al. (2008) Pathogens of domestic and free-ranging ungulates: global climate change in temperate to boreal latitudes across North America. Rev. Sci. Tech. Off. Int. Epizoot. 27, 511-528

28 Hoberg, E.P. et al. (2008) Integrated approaches and empirical models for investigation of parasitic diseases in northern wildlife. Emerg. Infect. Dis. 14, 10-17

29 Jenkins, E. et al. (2006) Climate change and the epidemiology of protostrongylid nematodes in northern ecosystems: Parelaphostrongylus odocoilei and Protostrongylus stilesi in Dall's sheep (Ovis d. dalli). Parasitology 132, 387-401

$30 \mathrm{Kutz}$, S. et al. (2005) Global warming is changing the dynamics of Arctic host-parasite systems. Proc. R. Soc. B 272, 2571-2576

$31 \mathrm{Kutz}$, S.J. et al. (2009) The Arctic as a model for anticipating, preventing, and mitigating climate change impacts on host-parasite interactions. Vet. Parasitol. 163, 217-228

32 Chan, M-S. et al. (1997) Transmission patterns and the epidemiology of hookworm infection. Int. J. Epidemiol. 26, 1392-1400

33 Chandler, A. (1929) Hookworm Disease: Its Distribution, Biology, Epidemiology, Pathology, Diagnosis, Treatment and Control, Macmillan

34 Chang, K. (1949) Studies on Hookworm Disease in Szechwan Province, West China, Johns Hopkins Press

35 Cort, W. et al. (1926) Researches on hookworm in China. Am. J. Hyg. Monograph series no. 7, pp. 398

36 Nawalinski, T. et al. (1978) Population biology of hookworms in children in rural West Bengal. I. General parasitological observations. Am. J. Trop. Med. Hyg 27, 1152-1161

37 Nawalinski, T. et al. (1978) Population biology of hookworms in children in West Bengal. II. Acquisition and loss of hookworms. Am. J. Trop. Med. Hyg. 27, 1162-1173

38 Schad, G. et al. (1983) Human ecology and the distribution and abundance of hookworm populations. In Human Ecology and Infectious Diseases (Croll, N. and Cross, J., eds), pp. 187-223, Academic Press

39 Hoagland, K. and Schad, G. (1978) Necator americanus and Ancylostoma duodenale: life history parameters and epidemiological implications of two sympatric hookworms of humans. Exp. Parasitol. $44,36-49$

40 Anderson, R. and May, R. (1991) Infectious Diseases of Humans: Dynamics and Control, Oxford University Press

41 Intergovernmental Panel on Climate Change (2007) Climate Change 2007: Impacts, Adaptation and Vulnerability. Contribution of Working Group II to the Fourth Assessment Report of the Intergovernmental Panel on Climate Change, Cambridge University Press

42 Brooker, S. et al. (2002) Use of remote sensing and a geographical information system in a national helminth control programme in Chad. Bull. World Health Organ. 80, 783-789

43 Brooker, S. et al. (2001) Using NOAA-AVHRR data to model human helminth distributions in planning disease control in Cameroon, West Africa. Photogramm. Eng. Remote Sensing 68, 175-179

44 De Clercq, D. et al. (1995) Schistosoma and geohelminth infections in Mali, West Africa. Ann. Soc. Belg. Med. Trop 75, 191-199

45 Hoberg, E.P. (2010) Invasive processes, mosaics and the structure of helminth parasite faunas. Rev. Sci. Tech. Off. Int. Epizoot. 29, in press

46 Patz, J. et al. (2008) Disease emergence from global climate and land use change. Med. Clin. N. Am. 92, 1473-1491 
47 Brooks, D. and Hoberg, E.P. (2006) Systematics of emerging infectious diseases: from management to solution. J. Parasitol. 92, 426-429

48 Wolfe, N. et al. (2007) Origins of major human infectious diseases. Nature 447, 279-283

49 Lafferty, K. (2009) The ecology of climate change and infectious diseases. Ecology 90, 888-900

50 Randolph, S. (2009) Perspectives on climate change impacts on infectious diseases. Ecology 90, 927-931

51 McMichael, A. (2008) Environmental change, climate and population health: a challenge for inter-disciplinary research. Environ. Health Prev. Med. 13, 183-186

52 Rogers, D. and Randolph, S. (2006) Climate change and vector-borne diseases. Adv. Parasitol. 62, 345-381

53 Pascual, M. et al. (2008) Shifting patterns: malaria dynamics and rainfall variability in an African highland. Proc. R. Soc. B 275, $123-132$

54 Yang, G-J. et al. (2007) Effect of temperature on the development of Schistosoma japonicum within Oncomelania hupensis, and hibernation of O. hupensis. Parasitol. Res. 100, 695-700
55 Yang, G-J. et al. (2005) A potential impact of climate change and water resource development on the transmission of Schistosoma japonicum in China. Parassitologia 47, 127-134

56 Zhou, X-N. et al. (2008) Potential impact of climate change on schistosomiasis transmission in China. Am. J. Trop. Med. Hyg. 78, 188-194

57 Malone, J. et al. (1998) A geographic information system on the potential distribution and abundance of Fasciola hepatica and $F$. gigantica in east Africa based on Food and Agriculture Organization databases. Vet. Parasitol. 78, 87-101

58 Peterson, A. et al. (2005) Modeling distributional shifts of individual species and biomes. In Climate Change and Biodiversity (Lovejoy, T. and Hannah, L., eds), pp. 211-228, Yale University Press

59 Lafferty, K. (2009) Calling for an ecological approach to studying climate change and infectious diseases. Ecology 90, 932-933

60 McMichael, A. et al. (2008) Global environmental change and health: impacts, inequalities, and the health sector. Brit. Med. J. 336, 191-194

61 Chen, Y. et al. (2008) Current status of soil-transmitted nematode infection in China. Biomed. Environ. Sci. 21, 173-179 